\title{
Do they understand more? Turkish EFL speakers perception of sentence stress in English
}

\author{
Anita Buczek-Zawiła \\ Pedagogical University of Cracow, Poland
}

\begin{abstract}
As one of the most prominent elements of intonation sentence stress frequently contributes to the meaning expressed by speakers. It most typically signals details of an utterance information structure, but it also performs a contrastive or emphasizing function, thus expressing focus in the spoken discourse. In English and many other languages its location, while exhibiting certain regularities it additionally determined by extra relevant or relative information. As such, either alone or in combination, it may communicate certain additional shades of meaning that, similarly to the contribution of sentence intonation, may escape the attention of EFL speakers.

The paper explores the comprehension sensitivity of Turkish speakers of English when it comes to identifying meaning details contributed by sentence stress. It investigates their awareness as detected through perception of variable sentence stress location. The target group are Turkish advanced speakers of English, with various levels of competence, and only sporadic phonetic training in English for part of them. In a perceptionbased experiment they were asked to identify the details they perceive. Their results were then compared and analysed, also in relation to what their native language (with a distinction into sentential and focal stress) adds in terms of this module of utterance intonation. Finally, their results were correlated with those achieved by Polish advanced speakers of English as investigated in a similar study conducted earlier. The interpretation of the results reveals that Turkish EFL speakers are more sensitive to the highlighting or contrastive function of sentence stress, achieving overall better result here than when they are to judge its contribution to notion such as politeness or impatience. They are also rather competent at detecting the prominent element in an utterance.
\end{abstract}

Keywords: sentence stress, discrimination, phonetic training, focus, contrast

\section{Introduction}

Sentence stress plays an important role in English verbal communication, since there seems to be a close relationship between information status and the location of the sentence prominence peak. Incorrectly applied it may confuse interlocutors, and even break down a conversation. It is also challenging for EFL learners to master as it is neither easy for them to perceive nor to produce phrasal stress. The concept and its use apparently must first get grounded in the minds of speakers in order to be used later according to what language or necessity dictates. Successful perception, therefore, is the first prerequisite for acquisition and 
ultimately production, hence the preoccupation of this paper is with perceptual sensitivity to this module of intonational structure of language.

As one of the most prominent elements of intonation, sentence stress may and frequently does contribute to the meaning expressed by speakers. As observed by Nilsenová and Swerts (2012: 77), the specific prosodic functions differ across languages. In its default application, it most typically signals details of an utterance information structure. However, it also performs a contrastive or emphasizing function, thus expressing focus in the spoken discourse. In English and many other languages its location, while exhibiting certain regularities is additionally determined by extra relevant or relative information, as determined in the speakers' minds and dictated by actual use. As such, either alone or in combination with other elements of utterance prosody, it may communicate certain additional shades of meaning that, similarly to the contribution of sentence intonation, may escape the attention of EFL learners.

This paper explores the comprehension sensitivity of Turkish speakers of English as a Foreign Language when it comes to identifying meaning details contributed by sentence stress. It investigates their awareness as detected through perception of variable sentence stress location. The target group are Turkish advanced speakers of English, with various, though generally advanced, levels of competence, where part of them received infrequent occasional phonetic training in English oral skills, also with respect to sentence stress practice. Most of them, however, remain phonetically untrained. In a perception-based experiment they are to identify the details they perceive. Their results are then compared and analysed, also in relation to what their native language (with a distinction into sentential and focal stress) adds in terms of utterance intonation. Finally, their results are correlated with those achieved by Polish advanced speakers of English as investigated in a similar study in BuczekZawiła (2015).

\section{Sentence stress in English and Turkish}

Not all information in a (spoken) discourse is equally important. In neutral discourse context, when words combine to form a sentence, one of them will typically receive greater prominence. The use of such phrasal/sentential stress in speech helps language users to both understand and deliver meaning in longer utterances. It is a general regularity that within utterances we emphasise tonic syllable in order to first and foremost highlight the most significant new information. It is only natural that speakers will make certain assumptions as to what is the given or the new information and express the distinction accordingly. And this function of signalling information structure is seen as the primary one for sentential stress (Szwedek 1989, Archibald 1997, Harris 2014). Katie Harris (2014: 29), though, argues that in the opinion of many researchers newness and givenness are not dichotomous entities, but points on a scale, where both discourse proximity and syntactic relations will be of significance.

Ladd (2008) explains further the distinctions in the functions of sentence stress, labelled as the normal stress view and the highlighting view. According to the former, there is one 
pattern of prominence that can be specified by rule for every sentence and such normal stress has no meaning or functions, it is the direct outcome of the operations of phonological rules on surface syntactic structures. A deviation from such normal stress will always involve signalling contrast or emphasis - hence the different label "contrastive stress". They are largely unpredictable and therefore governed paralinguistically. The latter, that is the highlighting view, essentially emphasised the idea that what speakers decide to highlight thus focus on - is not a matter of grammar, but rather of what they are trying to say in the specific circumstances that the discourse takes place. What resides in speakers' minds is essentially unpredictable, though may occasionally be related to societal factors. In this view, if 'accent distribution functions as a 'prosodic pointer' to highlight new/contrastive information and render given information less salient" (Harris 2014: 29), a clear and sharp divide between normal and contrastive stress cannot be obtained, as these will represent the extreme ends of informativeness continuum.

Sawicka (1988: 169) maintains that acoustically the three major factors such as fundamental values of $\mathrm{F}_{0}$ frequency as well as duration and intensity collaborate to constitute the melodic contours of which phrasal stress is part. The actual acoustic make-up of the contours is straightforwardly correlated with the utterance and text meaning, thus far possibly performing a distinctive function. Text segmentation into phrases, through identification of pauses with identical or fairly similar $\mathrm{F}_{0}$ melodic line, can thus be meaning relevant. Sawicka (1988: 173) further clarifies that any deviation in what is the regular prominence pattern, as manifested in the change of any of the prominence parameters, signals a shift from the logical, rhematic accent to the emphatic or emotional. It is emphasised, though, that the boundary between the rhematic and the emphatic accent is often difficult to establish, both from the point of view of its communicative function (frequently, the rhematic and the emotional functions are realised simultaneously in an utterance) as well as in view of the means that express those functions (Sawicka 1988: 174). It appears that the "norm", the prevailing tendency in a good number of languages is for the main accent to occur near the end of a phrase or sentence.

Katie Harris (2014: 28) believes English to belong to what she terms "plastic languages", one characteristic of which is seen in the prosodic marking of referents which have been previously mentioned or are expected from a discourse. Such languages have a relatively fixed word order but a rather flexible prosodic structure. "While words cannot be easily moved between different positions in a sentence, readers are relatively free to accent different words independent of their position" (Nilsenová and Swerts 2012: 83). This is prosodically achieved through what Ladd (2008: 231ff) terms "deaccentuation". He reports that English (and languages like English) "more or less insists on deaccenting repeated materials" (Ladd 2008: 232). This de-accenting of given information, however, is not a language universal, as pointed out by Caspers (2014). Typologically, again, there are also languages (the "non-plastic" ones) which strongly and consistently resist such deaccenting, where a fixed accent distribution is not related to conveying information status, yet even there the main accent can be shifted away from the neutral location under specific circumstances. Typically though, such nonplastic languages tend to vary their word order to shift words into locations where they will be 
understood as focused, thus employing structural constraints rather than pragmatic information (Casper 2014).

As for English, ${ }^{1}$ then, we talk about two major types of tonic placement. The neutral, unmarked or default type is one that does not express emphasis or contrast. This neutral tonicity typically on the last content word ${ }^{2}$ in a sentence or phrase most frequently signifies the rheme, or that part of the sentence which contains new information. Therefore, it can safely be said that the main function of the sentence stress is to single out the communicative centre of the sentence. Ladd (2008: 231) observes that since the English sentence stress can be influenced by the relative informativeness of words in an utterance, it is well known that the main accent tends not to be placed on elements that are repeated or "given" in the discourse or those that are vague or generic. If a different word, for example, a function word or a lexical word, besides the final one is to be stressed, this will be a case of contrastive stress. This means that the item which carries the accent is consciously emphasized in opposition to what might otherwise be the case, thus being the other type of tonic placement - the dislocated tonic. It can be further allocated to two major subtypes, namely the contrastive stress - where the shifting of nuclear stress can be exploited to change meaning by contrasting one word with another that could have been used in its place, e.g. "I love $\underline{Y O U}$ " (as opposed to some other guy/girl); and the corrective stress - here the effect of shifting tonic stress onto a particular word can be exploited to identify a mistake in something that was said, e.g. "Oops, I meant NEXT month, not THIS month".

Apart from languages like English in which rightmost main accent is the overwhelming norm, there are those which allow the tonic to occur earlier in a sentence. Languages with the subject-object-verb (SOV) word order represent one group of such instances. Turkish belongs to this typological subgroup. It is a SOV language that accentually distinguishes predicates and arguments, therefore the neutral or broad focus location for the main accent will fall on the object, especially so with indefinite pronouns (Ladd 2008: 250).

According to Göksel and Kerslake (2005: 37) in a simple sentence which is uttered as a single intonational phrase the unmarked position of primary stress is the stressable syllable of the word which is situated just before the predicate. Thus Turkish seems to treat predicates and arguments unequally with respect to phrasal accentuation. Two factors may decide upon the change in the stress position: the presence of clitics or negative suffix (which both attract sentential stress) as well as focusing a constituent, which may cause primary stress to appear on a constituent other than the one immediately preceding the predicate, as long as it remains preverbal. Göksel and Özsoy (2000: 224) argue that the surface syntax of Turkish has no designated focus position as focus is indicated there solely by means of stress. As such it can be assigned to any preverbal constituent. That is because any type of constituents can be focused provided it is heavily stressed at the same time. A less common strategy, as reported by Göksel and Kerslake (2005: 345), for focusing an element is to place stress on it in its

\footnotetext{
1 For more extensive discussion of sentences stress conditions and functions in English the reader is referred to Buczek-Zawiła (2015), Mott (2005) and Archibald (1997).

2 In the subject literature it is referred to as the accent-bearing location at the end of the sentence.
} 
unmarked position. As a result, ambiguous readings become possible, yet they may be resolved phonetically by the relative degree of stress.

According to Göksel and Özsoy (2000: 227) ${ }^{3}$ two types of sentence accent need to be recognized for Turkish: sentential stress proper, occurring in the immediately preverbal position, and focal stress. The latter is assigned at the level of $\mathrm{F}$ (ocus)-structure - a projection of S-structure marked for Topic and Focus. They write:

'We take stress to be the indicator of the leftmost boundary of the focus field. A phrase which denotes nonrecoverable information has to occur in the focus field, whether it be directly under the stressed position or anywhere to the right of this position, as long as it is preverbal.'

(Göksel and Özsoy 2000: 225)

Thus, the areas between the constituent which takes focal stress and the position indicative of the verbal complex is where the non-recoverable information is to be found.

The situation becomes blurred not when two elements compete for accent - since the leftmost bears it - but because there is only one stress per simple sentence in Turkish. Since all phrases are stressed on their left-branching nodes, the Verb Phrase is no exception and so the immediately preverbal position is the most plausible site for the main sentential accent. It is also possible - though much less plausible - that this position can also bear focal stress. Which one it is can only become apparent through phonetic clues and evidence with contrastive focus.

All this testifies to the fact that although largely having to do with the function of singling out the communicative centre of the sentence, the sentence stress in Turkish works slightly differently than it does in English. The existence of cross-linguistic differences and variability in sentence stress and prosodic marking of information structure will naturally mean that speakers of languages other than English, when speaking it, may decode the message in a different way than native speakers do. They may also produce it in positions different than the typical. Therefore, the acquisition of these properties may prove difficult for EFL speakers.

\section{Motivation for the current study.}

It is interesting to be able to observe whether L1 Turkish speakers of English consciously perceive the intricacies of the English system. It has been noted (Ladd 2008: 239) that the production of sentence stress will largely depend on speaker's assessment of what is likely to be in the hearer's consciousness or at the centre of hearer's attention. The other end of communication - the hearer is likewise likely to contribute their perceptions and understandings. Therefore, the current investigations - like those in Buczek-Zawiła (2015) are heavily biased towards perception, in the hope that well-developed recognition awareness will translate into more conscious and more deliberate use of this particular suprasegmental feature.

3 For a slightly different view and interpretation see Çetin and Coşkun (2016). 


\subsection{The specific interest}

This research survey investigates several areas related to sentence stress use in L2 English as used by Turkish speakers. The can be expressed in terms of the following research aims:

- To determine whether speakers can auditorily discriminate between utterances with sentence prominence marked through sentence stress in English, that is, whether they recognize that an utterance contains a more prominent element

- To examine the speakers ability to interpret the meaning communicated through the different positions of the accent in English, especially that in terms of grammatical structure it differs from what they are familiar with in their own language

- $\quad$ To investigate the possibility of interactional relationship between the relevant abilities acquired through basic training in prosodic prominence marking: does better perception of meaning created through sentence accent is related to earlier experiences in producing relevant oral skills

- To compare the perception abilities of English sentence stress meaning awareness of Polish and Turkish EFL speakers, basing on the same material yet in conditions of different cross-linguistic variation

\subsection{The study}

\subsubsection{Participants}

An overall number of 74 respondents participated in the survey. Age-wise they range from 18 to 23 year of age $(S D=2.1086) .{ }^{4}$ They comprise the 2014 (or earlier) secondary school leavers, currently taking first year degree courses in the Department of Translation at Istanbul University (38 participants) as well as students of the third year in the same department (36 participants). Table 1 summarizes the information about the two groups. It should, however, be pointed out that the participants' gender, age details or specific experience with and in English were not taken into account when analyzing their performance. Rather, groupcharacteristic tendencies were tried to be extrapolated from the results obtained.

Table 1: The participants

\begin{tabular}{|c|c|c|c|c|}
\hline & \multicolumn{2}{|c|}{ YEAR 1} & \multicolumn{2}{|c|}{ YEAR 3} \\
\hline Total number & \multicolumn{2}{|c|}{38} & \multicolumn{2}{|c|}{36} \\
\hline Women & 16 & 22 & 17 & 19 \\
\hline Mean age - total & \multicolumn{2}{|c|}{19.263} & \multicolumn{2}{|c|}{22.27} \\
\hline SD & \multicolumn{2}{|c|}{1.08} & \multicolumn{2}{|c|}{1.79} \\
\hline Women & 19.375 & 19.181 & 22.64 & 21.94 \\
\hline Phonetic training & \multicolumn{2}{|c|}{ none } & \multicolumn{2}{|c|}{ occasional, unsystematic } \\
\hline
\end{tabular}

\footnotetext{
4 Plus one extra class member who was a mature student, participating in the classes as part of his rehabilitation program from the host penitentiary institution.
} 
Their estimated level of Proficiency in English is slightly above the FCE level (save in one case, where the participant is known to have passed the CPE exam and with a very good grade). All are untrained phonetically when it comes to English, though in the course of the degree they have classes called Oral Skills (Speaking), where they practice oral communication abilities.

\subsubsection{Procedure}

The experiment procedure was as follows: originally in 2014 two sets of short sentences were recorded for the purposes of the survey; a male native speaker of Polish read the Polish examples, a female native speaker of English read the English ones. The two sets were not translational equivalents of each other, but represented characteristic patterns of both languages. Of these only the English ones were selected for the present investigations. The sentences were then converted into MP3 files, labeled according the sequence of questions in the actual quiz. The actual survey consisted of 15 questions and took place between the 23-27 of March 2015. The participants were to read the question, listen to the relevant audio file or files and provide an answer, choosing from the options listed. Only one question was of a true/false type ( $\mathrm{Q} 13$ ). The questions called for recognition of a perceptual difference in the way two sentences were said, providing an interpretation of an utterance meaning or selecting a context in which a given sentence was likely to be heard. Occasionally, reference was made to speakers communicating other related notions such as politeness or impatience. There was no limit set on the number of times the participants could play the recordings, additionally they had no access to the written version of the utterances, so that in their judgments they had to rely solely on the auditory impressions. The full list of actual questions as well as the sentences serving as audio material are provided in the appendix to this paper. As an example, we show two instances below, together with the incriminated sentences:

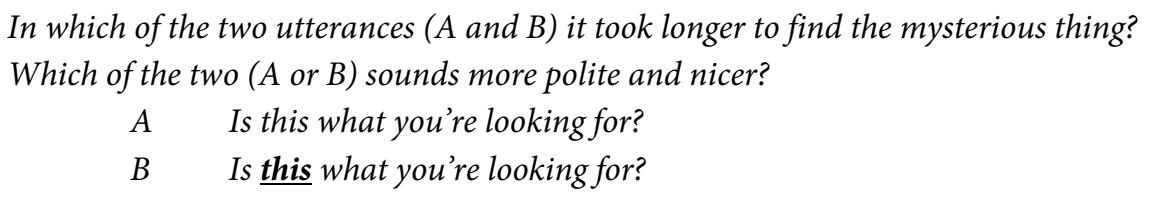

\subsubsection{Limitations}

In May 2013, during an Erasmus Staff Mobility exchange visit the then first year freshmen had some classes with the author where we practiced tonic placement in English and certain basic intonational contours as well as discussed the meaning contributed by these elements of sentence prosody. This group were the 2015 third year students, who constituted one group of participants, and were met again in March 2015 during another Erasmus Exchange. A month earlier, in February 2015, a colleague from the Pedagogical University of Cracow, Piotr Okas, had some classes with the same group(s), but he concentrated more on word stress, also in compounds, and on individual segment articulation. 
The same set of practice activities related to sentence stress as in 2013 was planned for the 2015 Year I, these, however, took place after they completed the quiz.

The format of the quiz was such that they had no access to the written form of the sentences, so that they had to rely solely on the aural input. For some among them this may have constituted additional point of difficulty. On the other hand, they still had to do a substantial amount of reading during the quiz, in order to be able to judge the recorded material accordingly and to mark the selected answer. The recordings themselves were somewhat idealistic, read at a pace that was slower than in ordinary conditions of casual conversation. This also could affect the participants performance in both groups.

Thus, we have two groups of respondents who differ in the years of experience as students in this particular department and, consequently, in having more training in their English language skills. Additionally, the older group had some instruction in the matters being tested beforehand, though the training was only occasional and unsystematic.

\subsection{The results}

The formula decided upon by the researcher was such that the participants were informed of the score they received in this quiz-format survey, both as feedback to individual questions as well as the final score of correct/incorrect answers. In that way it could be assured that the quiz itself was a good starting point for class practice that followed. For the purposes of analyzing the participants' performance, only the correct - incorrect ratio was taken into account, with no further analysis of the incorrect options selected (in the case where more than one invalid/erroneous interpretation was offered). Such evaluation procedure was decided upon a priori as a means of arriving at conclusions related to the relative difficulty of the perceptual tasks.

The general statistical information about the survey is summarized in the following table:

Table 2: Survey statistical information

\begin{tabular}{cc}
\hline Quiz name & Sentence stress survey_1 \\
\hline The quiz date & $23-27.03 .2015$ \\
\hline Total number of complete graded attempts & 74 \\
\hline Average grade of all attempts & $74.63 \%$ \\
\hline Median grade (for all attempts) & $74.34 \%$ \\
\hline Standard deviation (for all attempts) & $11.58 \%$ \\
\hline
\end{tabular}

The overall score overview for all participants is presented in the graph that follows: 


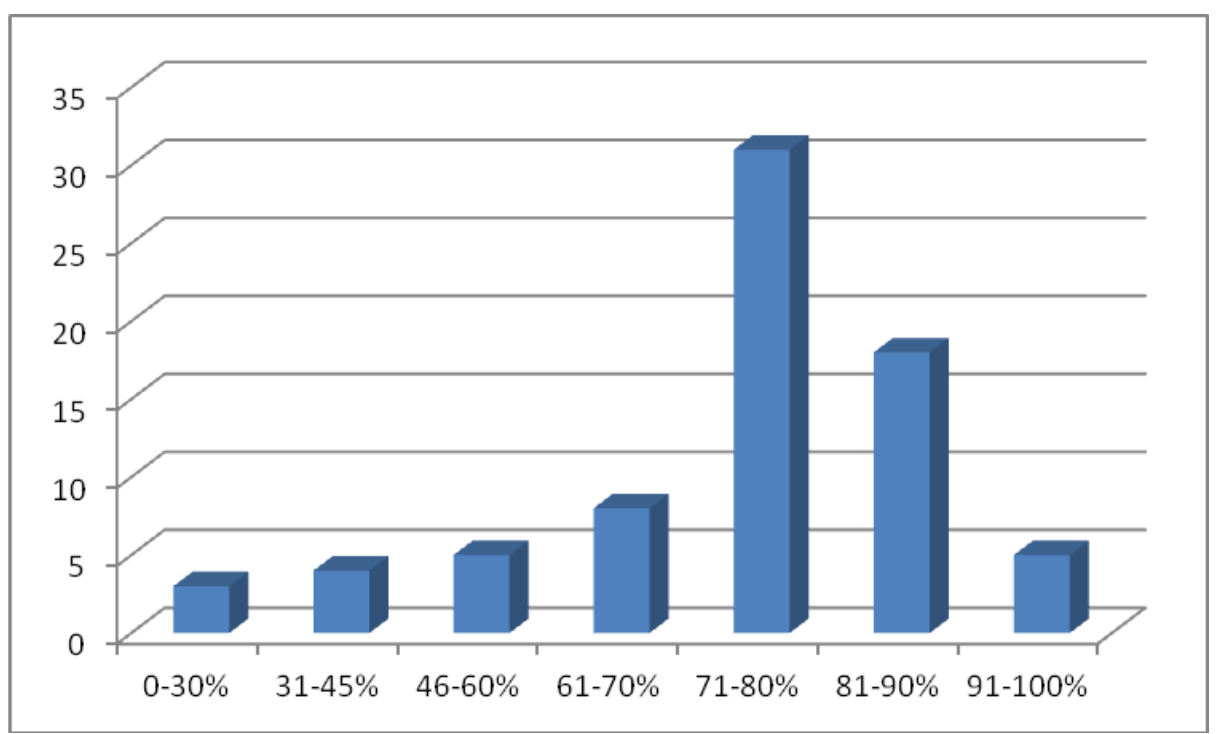

Figure 1: The overall score graph

The graph immediately demonstrates that the highest number of participants in both research subgroups achieved the score between 71 and 80 per cent of correct responses, with very few of them demonstrating either poor or very good perception and understanding of sentence stress related meanings. The results are not evaluated here as being desirably or satisfactorily high or low. They are presented in order to reveal the dominant pattern evident in students' perception skills.

However, when we compare the number of correct responses, as calculated from the statistical facility index, given in relation to scores obtained by Year 1 students with those of Year 3 students, the scores turn out to differ, though at first sight not terribly dramatically:

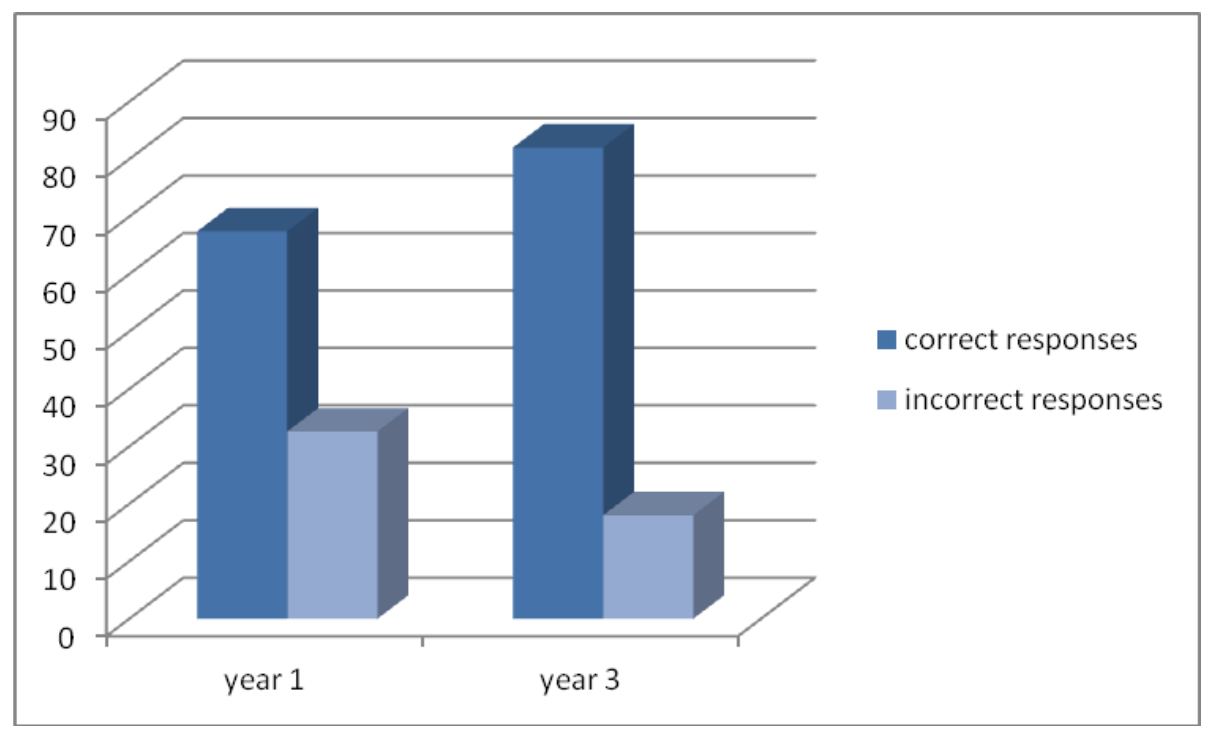

Figure 2: Scores of correct to incorrect answers for English in two groups of respondents

The results are respectively $67,41 \%$ and $82 \%$ for the percentage of correct interpretations of English utterances by Year I and Year III respondents. Additionally, the average scores on an item show that students are more aware of what is being said to them when contrastive stress 
is effected (e.g. question 11 and 12), not when notions such as politeness or other emotions are being communicated (questions 3 or 6 for example).

In order to evaluate whether the results obtained in the survey can be generalized beyond the population tested, a non-parametric statistical tool, the chi-square test, was used to determine the statistical significance (or lack thereof) of the actual scores. The particular test was believed to be appropriate here as the subjects' perceptions were judged to be either the right or the wrong interpretation of particular utterances. As such, the scale applied was nominal, not interval. For the purposes of calculation, an interactive online tool was used (Preacher 2001). Since the basic comparison related to how well - or how badly - respondents of different level of advancement performed on the questions pertaining to English sentence stress, the observed figures of correct and incorrect answers were entered into appropriate cells and then sums of elements within rows and within columns were computed. As a result, the following values were obtained:

Table 3: Chi-square basis

\begin{tabular}{lccc}
\hline & Turkish year 1 & Turkish year 3 & Sum of elements \\
\hline Correct answers & 67.41 & 82 & 149.41 \\
Incorrect answers & 32.59 & 18 & 50.59 \\
Total percentages & 100 & 100 & 200 \\
\hline
\end{tabular}

For the figures defined, the following chi-square values were obtained:

Table 4: Chi-square values

\begin{tabular}{cc}
\hline Chi-square & 5.632 \\
\hline Degree of freedom & 1 \\
\hline p-value & 0.0176355 \\
\hline Yates' chi-square $^{5}$ & 4.887 \\
\hline Yates' $^{\mathbf{p}}$-value & 0.02705967 \\
\hline
\end{tabular}

The calculated p-value of 0.017 certifies to the fact that the results obtained in the survey are statistically significant. At first sight it appears that there is a relation between the experience of participants as students of English, conceived of in terms of their being a year 1 or year 3 students, and their performance in the experiment. This is a substantially general observation and more detailed comments are necessary here.

The specific survey structure analysis for both groups of respondents is depicted in Table 5. The table presents the actual data for each question separately as obtained from the participants. The questions differed in terms of random guess scores, yet the correlation between this variable and the result obtained (the facility index figures) is not always straightforward. As could be expected, where the choice was between only two options, the scores are rather high. However, this is hardly surprising especially in view of the fact that the questions related to whether two sentences sound the same or different ( $Q 1$ and 2) or to whether the items in the utterance sound equally important (Q 13). Yet, even with questions

5 This correction is often employed to improve the accuracy of the null-condition sampling distribution of chisquare. 
where guessing was not very easy, namely those with multiple options provided, the scores were frequently relatively high (e.g. Q 11 for both groups, Q 4-6 for Year 3). The standard deviation figures, on the other hand, demonstrate that there were considerable differences among the individual participants in both groups in terms of their perceptual abilities. Still, they were on the whole better with purely auditorily orientated tasks than with those involving actual meaning or attitude interpretation.

Table 5: Survey structure statistics and analysis.

\begin{tabular}{c|cccc|cccc}
\hline & \multicolumn{4}{|c|}{ YEAR 1 } & \multicolumn{4}{c}{ YEAR 3 } \\
\cline { 2 - 9 } Question & Attempts & $\begin{array}{c}\text { Facility } \\
\text { index }\end{array}$ & $\begin{array}{c}\text { Standard } \\
\text { deviation }\end{array}$ & $\begin{array}{c}\text { Random } \\
\text { guess } \\
\text { score }\end{array}$ & Attempts & $\begin{array}{c}\text { Facility } \\
\text { index }\end{array}$ & $\begin{array}{c}\text { Standard } \\
\text { deviation }\end{array}$ & $\begin{array}{c}\text { Random } \\
\text { guess } \\
\text { score }\end{array}$ \\
\hline Q 1 & 38 & 89.47 & 22.62 & $50.00 \%$ & 36 & 100 & 0 & $50.00 \%$ \\
Q 2 & 38 & 89.47 & 22.62 & $50.00 \%$ & 36 & 97,22 & 16.66 & $50.00 \%$ \\
Q 3 & 38 & 68.42 & 47.10 & $50.00 \%$ & 36 & 88,88 & 47.10 & $50.00 \%$ \\
Q 4 & 38 & 68.42 & 47.10 & $33.33 \%$ & 36 & 86,11 & 47.10 & $33.33 \%$ \\
Q 5 & 38 & 73,68 & 44.62 & $33.33 \%$ & 36 & 86,11 & 44.62 & $33.33 \%$ \\
Q 6 & 38 & 52,63 & 50.60 & $33.33 \%$ & 36 & 69,44 & 50.60 & $33.33 \%$ \\
Q 7 & 38 & 57,89 & 50.03 & $33.33 \%$ & 36 & 75 & 50.03 & $33.33 \%$ \\
Q 8 & 38 & 60,52 & 49.53 & $33.33 \%$ & 36 & 75 & 49.53 & $33.33 \%$ \\
Q 9 & 38 & 52,63 & 50.60 & $33.33 \%$ & 36 & 72,22 & 50.60 & $33.33 \%$ \\
Q 10 & 38 & 52,63 & 50.60 & $25 \%$ & 36 & 69,44 & 50.60 & $25 \%$ \\
Q 11 & 38 & 73,68 & 44.62 & $25 \%$ & 36 & 83,33 & 44.62 & $25 \%$ \\
Q 12 & 38 & $68,42 \%$ & 47.10 & $25 \%$ & 36 & 75 & 47.10 & $25 \%$ \\
Q 13 & 38 & 84,21 & 36.95 & $50 \%$ & 36 & 94,44 & 36.95 & $50 \%$ \\
Q 14 & 38 & 61,15 & 48.88 & $20 \%$ & 36 & 77,77 & 48.88 & $20 \%$ \\
Q 15 & 38 & 57,89 & 50.03 & $20 \%$ & 36 & 77,77 & 50.03 & $20 \%$ \\
TOT 1LS & 38 & 67.41 & 9.45 & --- & 36 & 82 & 13.72 & -- \\
\hline & Mediana: 68.42 & & & Mediana: 78 & &
\end{tabular}

Without further going into details of the specific calculations, let us present certain dominant tendencies. The first observation to be made is that the average value score of insufficient interpretation of the meanings related to English utterances is attributable to the novelty of the phenomenon in the case of Year 1 respondents. The erroneous judgments made by the informants may be stemming from their relative uncertainty in the command of English - they do not feel particularly competent in their responses, but may also be associated with other factors, such as (too) much weight attached to performing well (information acquired through personal interviews via online communicators). The different mediana values in both groups also demonstrate that Year 3 students felt much more confident in their judgments as well as more sensitive to the minor intricacies.

A closer inspection of the attempts with average scores (between 71 to $80 \%$ ) reveals that in a vast majority of cases the ratio of good to erroneous answers was directly correlated to the type of question difficulty. The discrimination efficiency was highest with questions showing contrastive/corrective phrasal stress as opposed the default reading. 
To further compare the validity of these observations with what was determined in the case of Polish speakers of English as a Foreign language, a further comparison of results was computed. The scores obtained in a similar quiz in the spring of 2014 by Polish advanced learners of English were juxtaposed with the results of the Turkish students perceptions. It needs to be added, though, that the research on Polish students sentence stress awareness tried to correlate their perception of this phenomenon and its meaning contribution in Polish and in English. The data on English material had to be extrapolated. On the face value it looks alarmingly worse than that of the Turkish subjects. It needs to be borne in mind, however, that the Polish respondents had to simultaneously deal with two languages and two sets of sentences. Both groups were largely phonetically naive and comparably untrained.

Table 6: Chi-square basis for Turkish and Polish respondents

\begin{tabular}{lccc}
\hline & Turkish participants & Polish participants & Sum of elements \\
\hline Correct answers & 74.63 & 57.86 & 126.51 \\
Incorrect answers & 25.37 & 42.14 & 67.51 \\
Total percentages & 100 & 100 & 200 \\
\hline
\end{tabular}

Again, the non-parametric statistical chi-square test was used to evaluate the statistical significance of the actual scores.

Table 7: Chi-square values for Turkish and Polish respondents

\begin{tabular}{cc}
\hline Chi-square & 6.288 \\
\hline Degree of freedom & 1 \\
\hline p-value & 0.01215581 \\
\hline Yates' chi-square & 5.561 \\
\hline Yates' $\boldsymbol{p}$-value & 0.01836492 \\
\hline
\end{tabular}

The calculated p-value of 0.012 certifies to the fact that the results obtained in the survey are once again statistically significant with a potential to be generalised beyond the research sample. That is strengthened by the fact that the number of respondents in both experiments was comparable.

\subsection{Interpretation}

The interpretation of the survey results proves rather problematic. First of all, the survey involved recognition tasks rather than production. This necessarily eliminates certain broad or wide-ranging conclusions. In personal interviews, when trying to explain their willingness to participate in the survey, the respondents claimed they wanted to find out whether they can hear what is being said to them and interpret it unambiguously, that, in turn could constitute some initial training in actually using this element of sentence intonation more consciously. A good number of them actually proved very sensitive to this characteristic feature when asked about the context in which they would be likely to utter a particular sentence, for example as a warning, mild suggestion, to signal irritation etc. This, however, 
was mostly observed with third year students. They also stressed, though, that their impression is that in English it all sounds markedly different than in Turkish.

As for discriminating between the sentences where the only difference was in the position of sentence stress: one in its default, sentence-rightmost position, in the other it was moved leftwards to signal narrow focus, the respondents proved very perceptive, the success ratio was consistently rather high for both groups. ${ }^{6}$ This implies that their perceptive and discriminating skills have been put to good use. We can therefore legitimately claim that Turkish advanced speakers of English can auditorily discriminate between utterances with sentence prominence marked through sentence stress in English and they can recognize that an utterance contains an element which is more prominent than those in its neighbourhood. They also perceive the difference in marking the location of new and/or important information by a conspicuous change in pitch and the absence of such prosodic marking where less important or given information is communicated (Caspers 2014).

As to the speakers' ability to interpret the additional shades of meaning or focus communicated through the different positions of the accent, they turn out to be generally better when it comes to the non-default accent position. This is conceivably due to the fact that English is not their primary means of (oral) communication, being reduced to either class or not numerous social situations. The more extensive and frequent online communications in English are of no significance here, the oral element being utterly absent there. A closer analysis of the informants choices reveals their confusion with notions such as politeness, slight boredom, distinguishing between a simple statement of a fact and a suggestion as to the proposed course of action. It appears that the year I students have never before been made aware that such details can be communicated via accent and/or intonation, while Year III group could vaguely remember - but not immediately put to use - the minimal training they received two years before. In their opinion, this could be the factor that allowed them to generally perform better in the quiz. Another factor could possibly be that the grammatical structure of the English sentences differs from what they are familiar with in their own language, also in terms of default and marked positions for main accent. In their opinion, they were constantly involuntarily first looking for a verb.

The most difficult to determine is the possibility of interactional relationship between the relevant abilities in the two languages, English and Turkish: it cannot be unequivocally stated that better perception and meaning awareness created through sentence accent in their native language contributes to increasing the interpretational skills in the foreign one. Rather, those who obviously underachieved reported that it happened because they were constantly thinking of Turkish equivalents of the relevant sentences and the meanings thus created. Yet, in view of the fact that sentence prominence in Turkish is marked solely through prosodic means rather than sentence structure, it appears logical that there must be some relationship involved. What exactly is the nature of this interaction, and how powerful it can be, may possibly be better revealed when the production side of communication is examined. Even if we accept the view that Turkish may belong to the "non-plastic" (or "less-plastic") languages (Harris 2014), the recent research findings of Çetin and Coşkun (2016) strongly suggest that a

6 Compare averages for questions 4 and 5 in Table 5, likewise questions 10 to 12 there. 
good degree of prominence freedom is effected in the language, supporting their statement with experimental research and machine pattern recognition devices. As a result they state the following:

'Reserving the position before the verb for the stressed word or phrase as stated in many grammar and text books can only serve the function of limiting the creativity of Turkish language. This also reduces the verbal expression power of a language.'

(Çetin and Coşkun 2016: 7)

'In spoken discourse, proximity of the element to be emphasized to the verb and putting stress on the same word may lead to emergence of compounded stress. However, it is not necessary to put the main stress on a word or phrase only because it is next to the verb.'

(Çetin and Coşkun 2016: 8)

Therefore, it may at least be suspected that the documented growing plasticity of Turkish has a bearing on the actual awareness and performance of Turkish EFL speakers when it comes to English.

Finally, when comparing the achievements of Polish respondents in 2014 (Buczek-Zawiła 2015) and those of Turkish subjects, it looks like the latter outperformed the former. The demographic variables were similar in both experiments, and so was their competence in English. However, the Polish respondents had to simultaneously deal with two languages and two sets of sentences, which may have contributed to their poorer results in English. It also appears that Turkish, as a 'non-plastic' language, i.e. one in which the location of accents is more structurally constrained and largely intertwined with word order, produces in fact a more contrastive background against which some discoursal information is coded. It may thus be easier for speakers of Turkish to become sensitive to auditive prosody in a language where primary accents in utterances are primarily determined by pragmatic factors (Caspers 2014: 29).

\section{Conclusions}

This study confirmed the predictions that language users of a younger generation, that is those whose opportunities for actually using English and its command are on the whole much greater than those of their parents, do not fully realize that during speech they may be communicating shades of meaning not expressed through lexis or sentence structure. That seems to be a true prediction for Turkish as well as Polish advanced speakers of EFL. They are competent in the structure of language(s), they may even be familiar with certain nonstandard uses of that structure, but the idea to express more of what is in the mind simply through playing with the prosodic domain is not well-established among them. Additionally, since Turkish apparently belongs to languages that do not exploit accent distribution consistently for informational purposes, the speakers had to overcome the limitations stemming from cross-linguistic variability and potential prosodic transfer.

The ratio and the interaction may turn out to be different if a similar survey was conducted again, after some time. The new awareness, reportedly acquired through the present survey, can be strengthened through more practice in authentic social and 
professional communicative situations. A sort of unification of language structure and use as accepted in the language societies they function can be seen as desirable.

Additionally, it needs to be remembered that the judgments only concerned individual sentences, taken out of longer stretches of discourse. This fact may have contributed to the confusion evident in some of the answers provided.

Therefore it may prove interesting to see if the awareness of the role and meaning of sentence stress, and of other suprasegmental features can be developed and transformed into actual productive use.

\section{References}

Archibald, J. 1997. The acquisition of second language phrasal stress: a pilot study. In S.J. Hannahs, and M. Young-Scholten (eds.), Focus on phonological acquisition, 263-289. Amsterdam/Philadephia: John Benjamins Publishing Company.

Buczek-Zawiła, A. 2015. Do they know what they are saying? Sentence stress awareness of phonetically-untrained speakers. Linguistica Silesiana 36: 253-274.

Caspers, J. 2014. Pitch accent placement in Dutch as a second language. In J. Caspers, Y. Chen, W. Heeren, J. Pacilly, N.O. Schiller, and E. van Zanten (eds.), Above and beyond the Segments. Experimental linguistics and phonetics, 28-41. Amsterdam/Philadephia: John Benjamins Publishing Company.

Çetin, D., and M.V. Coşkun. 2016. Turkish sentence stress. The International Journal of Research in Teacher Education 7(2): 1-8.

Göksel, A., and A. Sumru Özsoy. 2000. Is there a focus position in Turkish? In A. Göksel, and C. Kerslake (eds.), Studies on Turkish and Turkic Languages, 219-228. Wiesbaden: Harrassowitz.

Göksel, A., and C. Kerslake. 2005. Turkish. A Comprehensive Grammar. London: Routledge.

Harris, K. 2014. The Prosodic Marking of Givenness in English and Italian: A Comparative Study. Newcastle and Northumbria Working Papers in Linguistics 20: 28-43.

Ladd, D. 2008. Intonational phonology. Cambridge: Cambridge University Press.

Mott, B. 2005. English Phonetics and Phonology for Spanish Speakers. Barcelona: Publicacions i Edicions de la Universitat de Barcelona.

Nilsenová, M., and M. Swerts. 2012. Prosodic Adaptation in Language Learning. In J. Romero-Trillo (ed.), Pragmatics and Prosody in English Language Teaching, 77-96. Dodrecht: Springer.

Preacher, K.J., 2001. Calculation for the chi-square test: An interactive calculation tool for chi-square tests of goodness of fit and independence [Computer software]. Available from http://quantpsy.org. [accessed: 17.09.2015]

Sawicka, I. 1988. Fonologia konfrontatywna polsko-serbsko-chorwacka, Wrocław: Ossolineum.

Szwedek, A. 1989. Funkcja akcentu zdaniowego. Rozprawy Komisji Językowej XXXV: 171-178.

\section{Appendix: the quiz format}

(the actual sentences are marked in italics)

1. Do these two sound the same or different (A and $B)$ ?

2. In which of the two utterances ( $A$ and $B$ ) it took longer to find the mysterious thing?

3. Which of the two (A or B) sounds more polite and nicer?

A Is this what you're looking for?

B Is this what you're looking for? 
4. This utterance $(\mathrm{C})$ can most probably be heard in which context?
a. A: She didn't come to see us B: She isn't .....
b. Even she wouldn't believe your story, she .....
c. You may be surprised to find out she .....

\section{She isn't that stupid.}

5. This utterance (D) can most probably be heard in which context?
a. A: She didn't come to see us B: She isn't .....
b. Even she wouldn't believe your story, she ....
c. You may be surprised to find out she .....
D She isn't that stupid.

6. This utterance (E) may be interpreted as:
a. Statement of a fact: I do not decide here
b. A litlle bit of speaker anxiousness ("Leave me alone")
c. A good piece of advice - I do not make decisions here
E Don't talk to me, Bob's the person you have convince.

7. Which of the utterances: F, G or none is the expected answer or reaction in the context given below:

$$
\text { You've given him a peach! }
$$

8. Which of the sentences: F, G or none is the expected answer or reaction in the context given below:

Are you sure he can do it with an apple?

9. Which of the sentences: F, G or none is the expected answer or reaction in the context given below:

He's a weakling, he can't even break an apple into halves!
$\mathrm{F} \quad$ He can break an apple into two.
G He can break an apple into two.

10. Match what you hear in $\mathrm{H}$ to the interpretations given below:
a. If were you, I would do it
b. In the normal course of events this will be your duty
c. No, not him, it's your task
d. This is my opinion

$\mathrm{H} \quad$ I think you should try it.

11. Match what you hear in I to the interpretations given below:
a. If were you, I would do it
b. In the normal course of events this will be your duty
c. No, not him, it's your task
d. This is my opinion

I I think you should try it. 
12. Match what you hear in J to the interpretations given below:
a. If were you, I would do it
b. In the normal course of events this will be your duty
c. No, not him, it's your task
d. This is my opinion

J I think you should try it.

13. In this utterance $(\mathrm{K})$ all words sound equally important: Yes/NO

K My sister doesn't like apples.

14. Choose the appropriate end to utterance $L$ from the options provided
a. ..., your sister is a different matter
b. ..., my wife, my daughter - they are a different story
c. ..., she prefers pears
d. ..., she loves them dearly and eats tons!
e. ..., she simply hates them
L My sister doesn't like apples.

15. Choose the appropriate end to utterance $M$ from the options provided
a. ..., your sister is a different matter
b. ..., my wife, my daughter - they are a different story
c. ..., she loves them dearly and eats tons!
d. ..., she prefers pears
e. ..., she simply hates them
M My sister doesn't like apples. 